\begin{tabular}{c} 
Volume and Issues Obtainable at Center for Sustainability Research and Consultancy \\
Journal of Business and Social Review in Emerging Economies \\
ISSN: 2519-089X (E): 2519-0326 \\
Volume 6: No. 1, March 2020 \\
JSRᄃ \\
Journal homepage: www.publishing.globalcsrc.org/jbsee \\
\hline
\end{tabular}

\title{
Improving Organizational Performance Through HRM-line Partnership: A Case of Higher Education Sector of Pakistan
}

\section{${ }^{1}$ Muhammad Waseem, ${ }^{2}$ Hazrat Bilal, ${ }^{3}$ Naveed Farooq, ${ }^{4}$ Wahid Raza}

${ }^{1}$ Assistant Professor, Department of Management Sciences, Hazara University Mansehra, Pakistan.

\author{
mwaseem@hu.edu.pk
}

${ }^{2}$ Assistant Professor, Center for Management and Commerce, University of Swat, Swat, Pakistan. hbilal@uswat.edu.pk

${ }^{3}$ Assistant Professor, Institute of Business Studies and Leadership, Abdul Wali Khan University, Mardan, Pakistan. Naveedfarooq151@gmail.com

${ }^{4}$ Assistant Professor, Government College of Management Sciences, Wana South Waziristan, Tribal District, Pakistan. wrkhattak287@yahoo.com

\begin{tabular}{l}
\multicolumn{1}{c}{ ARTICLE DETAILS } \\
\hline History \\
Revised format: February 2020 \\
Available Online: March 2020 \\
Keywords \\
HRM, Line Managers \\
involvement, Strategic Business \\
Performance and Decision \\
making
\end{tabular}

JEL Classification: D29, O15, H75

\section{ABSTRACT}

In todays' knowledge economy, the organizations focus on creating value through their most valuable resources i.e. human resource. For an effective management of human capital, a healthy partnership between HRM function and the line managers (heads of other departments/sections) is essential. Such type of partnership can augment the strategic success at different levels of organization. The main focus of this study is to evaluate how the partnership of line managers and HR managers in managing different HRM activities help a firm to achieve competitive advantage. The data was collected through the departments/section heads of public sector universities of Pakistan. The results indicate that when line managers actively participate in managing the HRM function of an organization, it yielded improved organizational outcomes. Therefore, the results of this study have an important implication for the managers of higher education institutes to devise mechanism to involve the line managers in managing HRM activities and thereby achieve higher performance outcomes in higher education sector of Pakistan.

\section{OPEN ACCESS}

(C) 2020 The authors, under a Creative Commons Attribution-

NonCommercial 4.0

Corresponding author's email address: hbilal@uswat.edu.pk

Recommended citation: Waseem, M., Bilal, H., Farooq, N., \& Raza, W.(2020). Improving Organizational Performance Through HRM-line Partnership: A Case of Higher Education Sector of Pakistan. Journal of Business and Social Review in Emerging Economies, 6(1), 321- 330

DOI: $10.26710 /$ jbsee.v6i1.1067

\section{Introduction}

In recent Human Resource Management literature, it is widely accepted that the line managers also have an important role in the management of human resources in an organization. Perry and Kulik (2008) 
argued that an effective partnership between the central HR function and the line managers can improve the people management function of an organization as many of HR tasks are being performed by the line managers. To effectively perform the strategic role and create value for an organization, HR managers have to delegate some of the important HR activities to the line managers (Kelly and Gennard, 2001; Renwick, 2003). Line managers are the middle level managers that are working at supervisory level positions in their departments or sections (MacNeil, 2003). Renwick and MacNeil (2002) argued that the responsibility of managing the human resources of an organization is no longer limited to the HR professionals, but it is equally shared by the line managers.

Strategic devolution of HRM function is referred to a process of engaging and involving the departmental heads in HR function like, HR decisions making, HR processes/activities and HR budgeting (Azmi and Mushtaq, 2015). It demands a rigorous effort by HR managers to discover methods and techniques in which to involve line managers to better align the HR practices with business environment. The participation of other managers is necessary because, they have a direct interaction with employees in many processes (Kulik and Bainbridge, 2006). In addition, as pointed out by the Gould-Williams (2007), the line manager's involvement also persuades workers to improve their performance.

Line managers are almost involved in all important subfunctions of HRM, however, their role become more important when they undertake the responsibilities of leadership and management skills in an organization (Budhwar, 2000). Ngugi (2016) argued that the line managers were found to have an important contribution in many HRM activities like HR planning, staffing, benefits, training \& development, performance evaluation and career development.

In institutes of higher learning, the heads of different academic departments and administrative section are also have an important role in different functions of HRM and without their active involvement, top management will not be able to achieve the desired results. Therefore, this study is designed to evaluate the level of their involvement in three important areas of HRM as identified by Azmi and Mushtaq (2015) i. e. HRM Decision Making, HR processes and activities and HR budgeting. In addition, it was also observed that how such involvement can lead to better organizational outcomes.

\section{Literature Review}

Because of changing business environment, HRM function is believed to be a key tool in achieving superior performance outcomes and creating a sustainable competitive advantage. Nowadays, HRM function is not taken as an administrative tool of the top management but it is accepted as a strategic business partner. To perform such an important role, the HRM is not only limited to HR specialists, the line managers can achieve HRM goals along with their own departmental goals (Mat, 2014). Organizations will be in a better position to compete in the market, when HR function is jointly managed by HR specialists and other managers. The decentralization of HRM functions to the line is widely discussed recent literature. Ngugi (2016), argued that the decentralization of HRM function to the line management is an emerging and prominent issue in many organizations and considered as an important tool to remain competitive in their environment. Terhalle (2009), pointed out that last two decades witnessed a lot of changes in the management of HRM. It is suggested that HR managers must share some of their responsibilities with line managers and increase the level of their autonomy in managing human resources. Now the HRM is not only the responsibility of HR specialists but the line managers must also be fully involved. Decentralization of HRM heavily depends upon the willingness and devotion of both the HR specialist and the line managers. Decentralization takes place in those organizations in which HR professional are willing to transfer HRM responsibility to the line management and line managers acceptance of such responsibility (Brewster and Larsen, 2000).

Azmi and Mushtaq (2015) suggested that in strategic HRM (SHRM) literature, decentralization of HRM function is accepted as an important aspect of people management. Now the line managers are progressively taking responsibilities of HRM and SHRM encourages a productive and complimentary 
cooperation among HR manager and the line managers in organizations.

Cunningham and Hyman (1995) explored that while converting the vision of HRM into reality, the role of line managers is more critical. They conducted an in-depth study in manufacturing and services sector of the UK and they recommended several issues to be addressed while supervising and managing HR through the line managers such as, the readiness of line managers to implement HRM approaches, the skills advancement of line managers to accomplish the HRM tasks and the HR professional's behaviors regarding line managers HRM role.

Boxall and Purcell (2008) stated that HRM cannot be limited to the few selected people in the organization. HRM is an organizational process and is related with all important aspects of management function. Line managers work closely with employees and have a major responsibility of subordinates' performance, thus their HRM role has an equal importance.

Several researchers (Khilji and Wang, 2006; Wright and Nishii, 2006) have identified that HR practices can be categorized in two categories, intended HR practices (mostly prepared and planned by HR specialists and top management) and intended HRM practices (HRM practices experienced the employees in an organization. They argued that the existence of well-made intended HRM practices but the employees will not only be affected by the management values, standards and recognized procedure but they are also affected by the actual workplace experiences of their day to day activities. The role of line managers is more important in effectively translating the intended HRM practices into reality (Terhalle, 2009).

Larsen and Brewster (2003) also highlighted an important issue while decentralizing the HRM. They argued that the decentralization may create some difficulties in balancing the expectations of HRM and line management. Similarly, Renwick (2003) suggested that the distribution of the HRM role among line managers and HR professional needs reassessment because of the issue of workers trust in line manager's capabilities to accomplish HRM activities. Purcell and Hutchinson (2007) argued that workers' satisfaction with the HR practices implemented by the line managers can positively effect worker attitudes and behaviors.

Ulrich (2005) noted that the decentralization of HRM is an important aspect of strategic HRM and identified four roles for managing human resources in an organization, which include change agents, business partners, employee champions and administrative experts. Townsend et al. (2012) highlighted that a role of line managers is significant in conveying the correct message to workers with respect to organizational goals. They suggested that organizations must invest in improving line manager's capabilities because they show a significant role in effecting workers' perceptions. They also recommended that more empirical research is necessary in other contexts to acquire a stronger understanding of line managers' role rather than that they are just involved in the operational activities of HRM function.

Overall the in existing literature, the importance of involving the line managers is widely acknowledged, however, researchers have different opinion regarding the sharing of HRM activities among the HRM function and other managers of organization. Azmi \& Mushtaq (2015) investigated that the line management roles have been identified in the organization and line mangers are now involved in core HRM functions. Cascon-Pereira et al. (2005) stated that HR specialist should play his role as a strategicpartner by developing appropriate HR practices as per organizational environment and the HRM activities which are more people focused and operational in nature need to be delegated to the line managers. Hartog, Boselie and Paauwe (2004) pointed out that maximum performance management practices (performance appraisal, feedback training, coaching, information sharing) are assisted and implemented by direct supervisors or line managers. Budhwar (2000) noted six components of involvement of line management in HRM practices which include, workforce expansion and reduction, recruitment, reward, training, health \& safety and the industrial relations. 
Ngugi (2016) also investigated that the line managers are also participating in other features of HRM, for instance recruitment and selection of employees, managing pay and benefit, training, evaluating performance of employees and career-development of workers. Morley et al (2006) suggested that line management is involved in HRM decision making, HRM processes and activities and HRM budgeting, while Hall and Torrington (1998) highlighted their involvement in budgetary controls. Overall, the line management is now increasingly accountable of HRM activities such as compensation, performance evaluation, training and motivation of employees.

Based on review of aforementioned studies on the subject, Azmi and Mushtaq (2015) summarized line managers' role in three broader categories i.e. HRM decision making, budgeting and HRM process/activities. Mainly relying on the suggestions of Azmi and Mushtaq (2015), the current research also evaluated the effects of line managers' involvement in HRM decision making, HRM budgeting and HRM process/activities on organizational outcomes. Thus, from the review of literature the following model is adopted for the current study:

Figure 2.1: Theoretical Framework

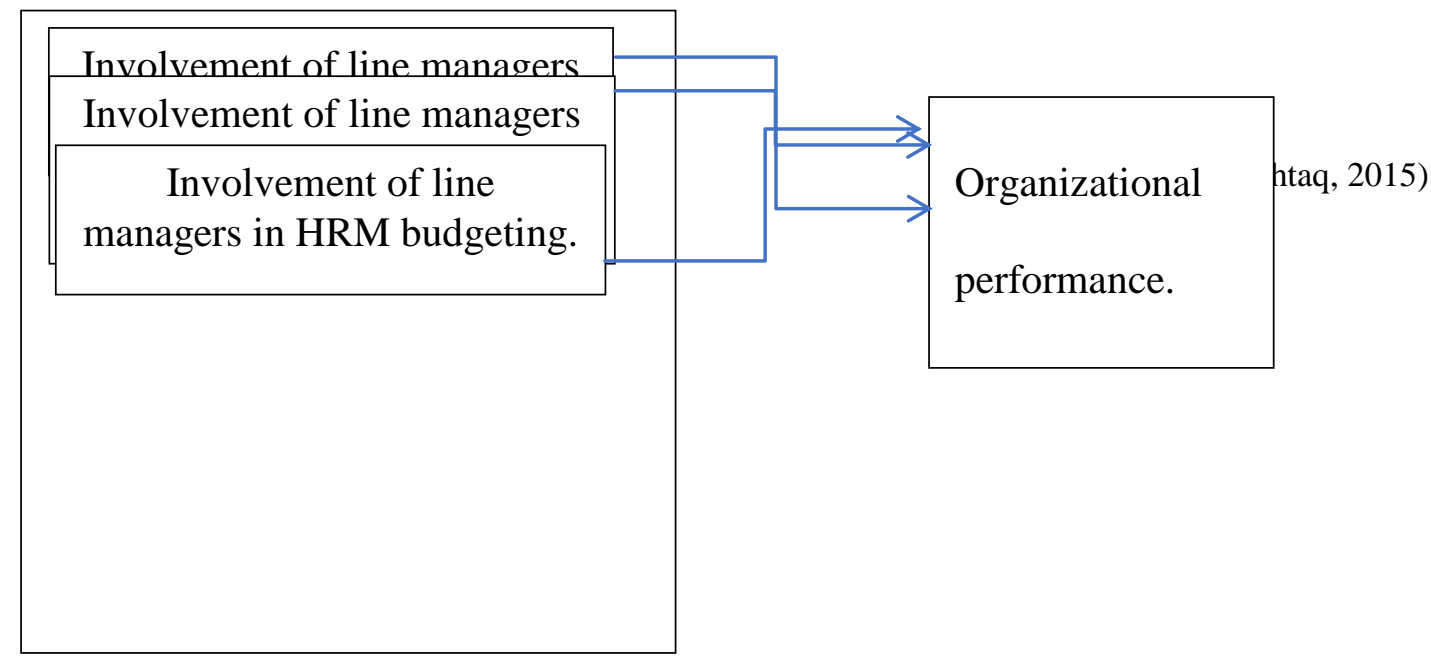

\subsection{Hypothesis of the study}

The main purpose of this study is to evaluate the level of involvement of line managers in management of human resources in organization and assessing its impact on organizational performance. On the basis of above mentioned theoretical framework, the following hypotheses were developed:

Hypothesis 1: Involvement of line managers in HRM decision making has a positive impact on organizational performance.

Hypothesis 2: Involvement of line managers in HRM practices/activities has a positive impact on organizational performance.

Hypothesis 3: Involvement of line managers in HRM budgeting has a positive impact on organizational performance.

\section{Methodology}

This study is based on quantitative approach with an assumption that line managers involvement in HRM has a positive effect on organizational performance. The quantitative approach is considered more to evaluate the relationship among different variables. The study was conducted in higher education sector of Pakistan. Higher education sector witnessed a tremendous growth in last two decades. The data was collected from the heads of different departments and sections of four public sector universities. A multistage sampling technique was used to draw the sample. In first stage, the four public sector universities were selected which are located in Hazara Division of Pakistan. In second phase the heads of departments/sections were selected from each university. Data was collected through a structured questionnaire and the responses regarding the level of their involvement in HRM functions were recorded 
on five-point Likert scale. There were $141 \mathrm{HoD} / \mathrm{HoS}$ in four selected universities, and the questionnaires were distributed among all the line managers, however, we received backed 105 questionnaires. Out of 105 questionnaires, the 101 were complete and used for data analysis. The details are given in table 3.1. The data was analyzed by using correlation and regression analysis.

Table 3.1 Population and Responses

\begin{tabular}{|l|l|l|l|}
\hline S. No & University & Population & Valid Responses Received \\
\hline 1 & $\begin{array}{l}\text { Hazara University Mansehra } \\
\text { (HU) }\end{array}$ & 52 & 36 \\
\hline 2 & University of Haripur & 31 & 22 \\
\hline 3 & $\begin{array}{l}\text { Abbottabad University of Science } \\
\text { and Technology (AUST) }\end{array}$ & 27 & 22 \\
\hline 4 & $\begin{array}{l}\text { COMSATS University Islamabad } \\
\text { (CUI) Abbottabad Campus }\end{array}$ & 31 & 21 \\
\hline & Total & $\mathbf{1 4 1}$ & $\mathbf{1 0 1}$ \\
\hline
\end{tabular}

\subsection{Measures}

The main purpose of this study was to evaluate the level of involvement of line managers in HRM functions and its impact on organizational performance. Independent variables of the current study are involvement of line managers in HRM decision making, HRM process/ activities and HRM budgeting and dependent variable is organizational performance.

Questionnaire was adopted from the previous research studies. There are two sections in the questionnaire, section A consist of 45 questions associated with the variables of the study while section B consist of 5 question related to the demographic information of respondents.

Involvement of line managers in HRM is the main independent variable, however we have taken all three dimensions of involvement as a separate variable i.e. Line manager's involvement in HRM decision making, HRM processes/activities and HRM budgeting.

\subsubsection{Involvement of line managers in HRM Decision making}

The involvement of line managers in HRM decision making is evaluated to explore the level of participation of line managers in HRM decisions making and policy development. The involvement of line managers in HRM decision making was evaluated though six items developed by Azmi and Mushtaq, (2015).

\subsubsection{Involvement of Line Managers in HRM Processes and activities}

The involvement of line managers in HRM process/activities refers to the level of participation of line management in day to day HRM activities. It is also measured through six items scale developed by Azmi and Mushtaq, (2015).

\subsubsection{Involvement of Line managers in HRM Budgeting}

The involvement of line managers in HRM budgeting refers to the participation of line management in financial matters related with HRM activities. A six item scale developed by Azmi and Mushtaq, (2015) was used to measure this variable.

\subsubsection{Organizational Performance}

Organizational performance has no agreed definition because organizations diverge with industries and different situations. From the rational goal model, organizational performance may be defined as the amount to which organizational objectives are attained (Price 1972). Universities or institutes of higher learning are built for knowledge formation and transformation in the societies. Performance measurements of universities have been concentrated on academic excellence. From the last ten years, the 
ideologies of universities as corporate actors have progressively gained prominence (De Boer et al. 2007). However, universities goals remain vague are broader in scope, such as support to the regional development, contribution to social impact, world class researches etc. Like many business organizations, universities are not directed by the philosophies of profit-maximization; therefore, the performance assessment can't follow the traditional rational goal model, other factors like general conditions of financial health, capability to acquire resources and capability to satisfy the stakeholders are also important (Sowa et al. 2004).

Cameron, (1978) proposed and used 9 dimensions (KPIs) for evaluating organizational performance of higher education institutes which include: students educational satisfaction, students' academic development, students career development, students personal development, faculty and staff satisfaction, professional development of the faculty, openness of the system and community interactions, ability to acquire resources, and overall organizational health. Several research studies (Ballard, 2013; Wang, Chich-Jen, and Mei-Ling, 2010)) used these KPIs for measuring the organizational performance of higher education institutes. Therefore, this research study also utilized the Cameron 9 KPIs with 27 items to measure university performance. The HODs and HOSs were asked to assess the performance of universities/DAI on each dimension.

\subsubsection{Demographic variables}

Age, gender, qualification and professional experience of the respondents were taken as demographic variables.

Table 3.2: Measures

\begin{tabular}{|c|c|c|c|c|}
\hline S. No & Variable & No of Items & Chron Bach $\alpha$ & Source \\
\hline 1 & $\begin{array}{ll}\text { Involvement of } & \text { Line } \\
\text { Managers in } & \text { HRM } \\
\text { Decision Making } & \end{array}$ & 6 & .74 & $\begin{array}{l}\text { (Azmi } \text { and } \\
\text { Mushtaq, 2015) }\end{array}$ \\
\hline 2 & $\begin{array}{l}\text { Involvement of } \text { Line } \\
\text { Managers in } \\
\text { process/activities }\end{array}$ & 6 & .82 & $\begin{array}{l}\text { (Azmi and } \\
\text { Mushtaq, 2015) }\end{array}$ \\
\hline 3 & $\begin{array}{lll}\text { Involvement of } & \text { Line } \\
\text { Managers } \\
\text { Budgeting }\end{array}$ & 6 & .86 & $\begin{array}{l}\text { (Azmi and } \\
\text { Mushtaq, 2015) }\end{array}$ \\
\hline 4 & $\begin{array}{l}\text { Organizational } \\
\text { (Universities) Performance }\end{array}$ & 27 & .79 & (Camron, 1978) \\
\hline
\end{tabular}

\section{Data Analysis and Results}

This section presents the results of the study, the demographic information of respondents is presented in the first the while hypotheses testing results are presented in the next part.

\subsection{Respondents' Profile}

Out of 101 of valid responses used in data analysis, $95 \%$ of the respondents were male. It shows that the management of higher education sector in Pakistan is highly dominated by male members of the society. Similarly, the majority of respondents, about $52 \%$ were in the age group of 30 to 39 years, $19 \%$ were in age group of 30-39 years, $29 \%$ of total respondents were in age group of 50-59 years. The level of education was also observed, and it was found that majority of the respondents (64\%) are highly qualified and possess the $\mathrm{PhD}$ degrees in their field. $22 \%$ of the respondents were having M.Phil/MS degrees while remaining $14 \%$ were having Master degrees.

Similarly, the respondents also reported their length of service in current organization. It shows that length of service reported by $52 \%$ of the respondents is in the range of 6 to 10 years, $34 \%$ of the in the 
range of 3 to 5 years, while $14 \%$ of the respondents are working with the existing organization from more than 10 years.

\subsection{Reliability Analysis}

The reliability of instrument was checked through Cronbach's alpha. It was found that the reliability of all the variables of the study is above the threshold value of 0.7 which shows that the instrument used in this study is reliable and all items have comparatively high internal consistency. The values of Cronbach;s alpha are presented in table 3.1

\subsection{Correlation Analysis}

The correlation results show that the dependent and independent variables used in this study are positively correlated. The results are shown in table 4.1.

Table 4.1: Correlation Analysis

\begin{tabular}{|l|l|l|l|l|}
\hline & LMI-DM & LMI-PA & LMI-B & OP \\
\hline LMI-DM & 1 & & & \\
\hline LMI-PA & $.504 * *$ & 1 & & \\
\hline LMI-B & $.723 * *$ & $.647^{* *}$ & 1 & \\
\hline OP & $.748 * *$ & $.751^{* *}$ & $.848^{* *}$ & 1 \\
\hline
\end{tabular}

*Correlation is significant at 0.01 level (2- tailed)

\subsection{Regression Analysis}

After correlation analysis, the regression analysis was used to test the hypotheses of the study. In table 4.8 , the $\mathrm{R}^{2}$ value of 0.82 shows that $82 \%$ of the change in organizational performance is caused by the independent variables i.e. involvement of line managers in HRM decision making, HRM process/activities and HRM budgeting.

Table 4.2: Regression Analysis

\begin{tabular}{|l|l|l|l|l|}
\hline Model & R & R Square & $\begin{array}{l}\text { Adjusted R } \\
\text { Square }\end{array}$ & $\begin{array}{l}\text { Standard Error } \\
\text { of the estimates }\end{array}$ \\
\hline 1 & .906 & .821 & .816 & .15433 \\
\hline
\end{tabular}

Coefficients

\begin{tabular}{|l|c|c|c|c|c|}
\hline \multirow{2}{*}{ Model } & \multicolumn{2}{|c|}{ Unstandardized Coefficients } & $\begin{array}{c}\text { Standardized } \\
\text { Coefficients }\end{array}$ & \multirow{2}{*}{ T } & \\
\cline { 2 - 4 } & $\boldsymbol{\beta}$ & Std. Error & $\boldsymbol{\beta}$ & & \\
\hline Constant & .256 & .202 & & 1.268 & .208 \\
\hline ILM-DM & .253 & .061 & .259 & 4.156 & .000 \\
\hline ILM-PA & .296 & .050 & .332 & 5.889 & .000 \\
\hline ILM-B & .367 & .058 & .446 & 6.318 & .000 \\
\hline
\end{tabular}

Dependent Variable: OP

Similarly, both $\beta$ value and $p$ value show that all three dimensions of line managers involvement in HRM are significant predictors of organizational performance. Line managers involvement in HRM decision making, HRM process/activities and HRM budgeting have a positive and significant impact on organizational performance. Hence all three hypotheses of the study are accepted.

\section{Discussion}

Overall, the results of study indicated that involvement of line managers in HRM function has a positive impact on organizational performance. First hypothesis was about the impact of line managers' involvement in HRM decision making on organizational performance. It was found that when line managers actively participate in HRM decision making, it will yield positive effects on organizational performance.

In second hypothesis, it was assumed that involvement of line managers in HRM practices/activities has a 
positive impact on organizational performance. The results of study approved the assumption and confirmed that like other sectors, line managers involvement in HRM activities and processes is a significant contributor in the performance of higher education sector.

In third hypothesis, it was hypothesized that Line managers' involvement in financial matters of HRM has a positive impact on organizational performance. The hypothesis was confirmed through the results and it was found that when line managers are in involved in HRM budgeting, it will further improve the utilization of HRM funds and thereby will yield positive organizational outcomes.

These results confirm the results of previous studies (e.g. Azmi and Mushtaq, 2015) and contribute in existing body of knowledge by confirming these results in the context of higher education sector of Pakistan.

\section{Conclusion}

The main objective of the current study was to evaluate the impact of line managers' (HODs \& HOSs) involvement in HRM functions on organizational performance. The study was an attempt to provide some significant evidences to the top management of universities, HR Professional and decision-makers regarding the significant of line managers in the management of human resources in their organizations. The results of the study suggested that the universities can improve their performance by involving the HODs and HOSs in the management of HRM function in their organizations. The line managers can effectively contribute in staffing, human resource development, compensation, performance evaluation etc. Similarly, their active involvement in HRM will improve firms' HRM capabilities and it will help them to achieve competitive advantage. Line managers relatively have a close interaction with employees and their actions are more visible to the employees as compared to HR specialist. Therefore, an effective partnership of line managers and HRM specialist will not only facilitate in designing useful HR policies and plans but it will also ensure effective implementation of HR practices.

\section{Theoretical and Practical Implications}

The current study has some important contributions in the existing body of knowledge by empirically testing the model of strategic involvement of line managers in HRM functions and its impact on organizational performance. Although the theoretical framework was adopted from the previous studies (e.g. Azmi and Mushtaq, 2015; Ngugi, 2016), but the results of our study further extended the model by confirming its utility in service sector like the higher education. Previous studies are mainly conducted in business organizations in which the profitability is the main concern. Further, this study evaluated the university performance through 9 KPIs identified by the Camron, (1978). It covers all the important aspects of university performance from the perspective of various stakeholders.

The findings of the researcher are helpful for organizations especially the universities to improve their performance by paying attention to the important role of line managers in HRM. It will further pave the way to involve line managers in important HRM decisions. Previously, the role of line managers was limited only to the implementation of some of HR practices, but our findings highlighted that their role is equally important in HRM as it is in their own departmental obligations. The HRM goals can not be effectively achieved without the active involvement of line Managers in HRM. The top management of universities now have to acknowledge that they have to focus on improving organizational performance as public funding to universities is shrinking day by day. The universities are facing with the issues of sustainability, even they have highly qualified staff and faculty. In today's knowledge economy, the human capital of an organization can be a key for the achievement of competitive advantage in organizations. The management of universities can achieve self-sustainability by effectively utilizing the potential of highly qualified knowledge workers. This can be effectively done by developing a productive partnership between HR managers and heads of different departments/sections.

Universities can involve HODs and HOSs in HRM function by providing them sufficient training, resources and an enabling environment equipped with modern technology. The line managers work very 
closely with their employees; therefore, they have more knowledge of constraints and potential of the employees. Their involvement will bridge the gap between intended HR practices and actual HR practices.

\section{Limitations of the Study}

Although the current study has suggested some of the important measures to improve the overall performance of the universities, there are some limitations of the study that are important to note. Firstly, the current study is cross sectional in nature and also based on self-reported data which may have a social desirability bias. To overcome such type of problem, a mix methodology approach may be adopted by future researchers. Moreover, this research study has selected only three dimensions of line managers involvement, so future studies need to identify other important areas of HRM in which the line managers can play their role. Further, future studies can improve this research by adding some relevant factors as moderating or mediating variables in the relationship between involvement and HRM performance. The data was collected through a structured questionnaire and the respondent of the study was bound to record their responses accordingly. For in depth analysis of the problems associated with such type of decentralization an open ended questionnaire can be more useful. This study was conducted only on four public sector universities located in Hazara division of Pakistan. Future studies may extend their studies at provincial or national level.

\section{References}

Azmi, F. T., \& Mushtaq, S. (2015). Role of line managers in human resource management: empirical evidence from India. The International Journal of Human Resource Management, 26(5), 616-639.

Boxall, P., Purcell, J., \& Wright, P. (2008). SCOPE, ANALYSIS, AND SIGNIFICANCE. The Oxford handbook of human resource management.

Ballard, P. J. (2013). Measuring performance excellence: Key performance indicators for institutions accepted into the Academic Quality Improvement Program (AQIP).

Brewster, C., \& Larsen, H. H. (2000). Flexibility in HRM: Contradictions in Organizational Survival. In Human Resource Management in Northern Europe (pp. 125-146). Blackwell Publishing.

Budhwar, P. S. (2000). Evaluating levels of strategic integration and devolvement of human resource management in the UK. Personnel Review, 29(2), 141-157.

Cunningham, I. and Hyman, J. (1999), "Devolving human resource responsibilities to the line: beginning of the end or a new beginning for personnel?", Personnel Review, Vol. 28 No. 1/2, pp. 9-27.

Cascón-Pereira, R., \& Valverde, M. (2014). HRM devolution to middle managers: Dimension identification. BRQ Business Research Quarterly, 17(3), 149-160.

Cameron, K. (1978). Measuring organizational effectiveness in institutions of higher education. Administrative science quarterly, 604-632.

Gould-Williams, J. (2007). HR practices, organizational climate and employee outcomes: evaluating social exchange relationships in local government. The International Journal of Human Resource Management, 18(9), 1627-1647.

Den Hartog, D. N., Boselie, P., \& Paauwe, J. (2004). Performance management: A model and research agenda. Applied psychology, 53(4), 556-569.

De Boer, H. F., Enders, J., \& Leisyte, L. (2007). Public sector reform in Dutch higher education: The organizational transformation of the university. Public Administration, 85(1), 27-46.

Khilji, S. E., \& Wang, X. (2006). Intended and implemented HRM: the missing linchpin in strategic human resource management research. The International Journal of Human Resource Management, 17(7), 1171-1189.

Kulik, C. T., \& Perry, E. L. (2008). When less is more: The effect of devolution on HR's strategic role and construed image. Human Resource Management: Published in Cooperation with the School of Business Administration, The University of Michigan and in alliance with the Society of Human Resources Management, 47(3), 541-558.

Kulik, C. T., \& Bainbridge, H. T. (2006). HR and the line: The distribution of HR activities in Australian organizations. Asia Pacific Journal of Human Resources, 44(2), 240-256. 
Kelly, J. N., \& Gennard, J. (2001). Power and Influence in the Boardroom. London: Routledge. MacNeil, C. M. (2003). Line managers: facilitators of knowledge sharing in teams. Employee Relations.

Morley, M., Valverde, M., Ryan, G., \& Soler, C. (2006). Distributing HRM responsibilities: a classification of organisations. Personnel Review.

Ngugi, E. W. (2016). Extent of Involvement of Line Managers in Human Resource Management Functions in Thika Water and Sewerage Company Limited.

Purcell, J., \& Hutchinson, S. (2007). Front-line managers as agents in the HRM-performance causal chain: theory, analysis and evidence. Human Resource management journal, 17(1), 3-20.

Price, J. L. (1972). The study of organizational effectiveness. The sociological quarterly, 13(1), 3-15.

Renwick, D. (2003). Line manager involvement in HRM: an inside view. Employee Relations.

Renwick, D., \& MacNeil, C. M. (2002). Line manager involvement in careers. Career Development International.

Sowa, J. E., Selden, S. C., \& Sandfort, J. R. (2004). No longer unmeasurable? A multidimensional integrated model of nonprofit organizational effectiveness. Nonprofit and voluntary sector quarterly, 33(4), 711-728.

Terhalle, A. M. (2009). Line managers as implementers of HRM: the effect of line managers' limitations on their HRM implementation effectiveness (Master's thesis, University of Twente).

Townsend, K., Wilkinson, A., Allan, C., \& Bamber, G. (2012). Mixed signals in HRM: the HRM role of hospital line managers 1. Human Resource Management Journal, 22(3), 267-282.

Ulrich, D., \& Brockbank, W. (2005). The HR value proposition. Harvard Business Press.

Wang, F. J., Chich-Jen, S., \& Mei-Ling, T. (2010). Effect of leadership style on organizational performance as viewed from human resource management strategy. African Journal of Business Management, 4(18), 3924.

Wright, P. M., \& Nishii, L. H. (2013). Strategic HRM and organizational behaviour: Integrating multiple levels of analysis. In J. Paauwe, D. E. Guest, \& P. M. Wright (Eds.), HRM and performance: Achievements and challenges (pp. 97-111). London: Wiley. 